\title{
$\mathrm{DNPH}$ Cartridge를 이용한 악취성 카르보닐화합물의 분석회수율 비교
}

홍원필 · 임승민 · 김기현

세종대학교 환경에너지융합학과

(2010. 6. 10. 접수, 2010. 10. 5. 승인)

\section{Comparison of recovery rates of DNPH-Cartridge sampler in the analysis of odorous carbonyl compounds}

\author{
One-Feel Hong, Sung-Min Lim, Ki-Hyun Kim ${ }^{\star}$ \\ Department of Environment \& Energy, Sejong University, Seoul, Korea \\ (Received June 10, 2010; Accepted October 5, 2010)
}

\begin{abstract}
요 약: 본 연구에서는 악취성 카르보닐화합물 $(\mathrm{CC})$ 의 채취에 많이 사용하는 DNPH cartridge의 분석 회 수율을 다양한 방법으로 평가하였다. 이를 위해, 각기 다른 3종류의 DNPH cartridge (A = Waters, B = Top trading, $\mathrm{C}=$ Supelco) 제품을 대상으로 5가지 CC 성분들에 대하여 총 9 가지 농도단계 $(33$ 2600 nmol)의 작업용 표준시료를 제조하였다. 그리고 이들 제품들을 이용하여, 카트리지 분석 방식별, 제품별 성능을 평가하였다. 본 실험의 결과, cartridge 제품에서 acetaldehyde와 propionaldehyde 성분의 blank를 일반적으 로 검출하였다. 검량 기울기 값을 비교하는 방식으로 5 가지 $\mathrm{CC}$ 성분에 대한 제품별 회수율 비교하였 다. 그 결과, 3 가지 제품 모두 CC 성분의 분자량이 증가할 경우 회수능이 감소하는 양상을 보였다. 그 리고 회수율의 변화추이를 percent error(\%)와 같은 변수로 살펴본 결과, $263 \mathrm{nmol}$ 부터 $1312 \mathrm{nmol}$ 농도 범위에서 가장 안정적인 경향을 나타냈다. 이러한 점을 감안할 때, 분석 대상 $\mathrm{CC}$ 에 대한 이상적인 농도 범위와 cartridge의 선택이 정확한 분석자료를 확보하는데 중요한 요인으로 작용한다는 것을 알 수 있다.

Abstract: In this study, the performance characteristics of DNPH sampling were investigated in the collection and analysis of 5 carbonyl compounds (CC) in air using the cartridge products produced by three different makers. For these experiments, gaseous standards of $5 \mathrm{CCs}$ were prepared to cover 9 concentration levels for each compound (33 2600 nmol). Some cartridge products exhibited relatively high blank values of acetaldehyde (AA) and propionaldehyde (PA). The recovery rates of all three cartridges showed moderate reduction as the molecular weight of CC increased. In addition, when the recovery rate was compared by percent error (\%), the most stable patterns were achieved in the intermediate concentration range of $263 \sim 1312 \mathrm{nmol}$ (in case of AA). The overall results of our study suggest that the optimal range of recovery for a given concentration range should be considered to obtain the most reliable data for the DNPH cartridge method.
\end{abstract}

Key words: DNPH cartridge, carbonyl compounds, recovery rate

Corresponding author

Phone : +82-(0)2-3408-3233 Fax : +82-(0)2-3408-4320

E-mail : khkim@sejong.ac.kr 


\section{1. 서 론}

아세트 알데하이드를 위시한 다수의 카보닐계 화합 물들(carbonyl compounds: $\mathrm{CC}$ )은 환경부에서 제정한 악취방지법의 주요 지정 악취성분으로서 중요한 의미 를 지닌다. ${ }^{1}$ 또한 이들은 흡연 과정에서 발생하는 유 해 성분으로도 잘 알려져 있다. ${ }^{2}$ 이와 같은 $\mathrm{CC}$ 성분 들의 중요성으로 인해, 이들에 대한 연구는 환경 관련 분야의 연구 주제로 다양하게 다루어져 왔다. ${ }^{3}$

$\mathrm{CC}$ 성분들의 채취는 크게 passive sampling 방식과 active sampling 방식과 같이 2 가지 유형으로 구분한다. ${ }^{4}$ 확산원리에 기초한 passive sampling 방식의 경우, 주 로 주택 또는 자동차의 실내공기 중 formaldehyde (FA) 등의 채취에 주로 적용하고 있다. ${ }^{5,6}$ 진공펌프를 이용 하는 active sampling의 경우, 실내공기는 물론 일반 환경대기 중 $\mathrm{CC}$ 를 채취하는데 용이한다. 따라서, 많 은 연구자들이 선호하는 방식에 해당한다. ${ }^{7-9}$ 특히 후 자의 경우, 화학적으로 불안정한 카보닐계 화합물들을 안정한 유도체로 형성시켜주는 2,4-DNPH를 코팅한 cartridge와 연계하는 방식을 위주로 활용하고 있다. ${ }^{10}$

본 연구는 지정 악취물질에 해당하는 총 5 가지의 알 데하이드 성분들((1) acetaldehyde: AA, (2) propionaldehyde: PA, (3) butyraldehyde: BA, (4) iso-valeraldehyde: IA, (5) valeraldehyde: VA)을 조사대상으로 선정하여 진행하였다. 일반적으로 $\mathrm{CC}$ 성분들에 대한 분석은 gas chromatography (GC) 방식과 high performance liquid chromatography (HPLC) 방식을 고려할 수 있다. ${ }^{11}$ 그 런데 $\mathrm{GC}$ 방식의 분석을 적용할 경우, HPLC 방식에 비해 상대적으로 분석감도가 낮고 저분자량의 $\mathrm{CC}$ 에 대한 재현성이나 감도에 대한 문제점이 발생할 수 있 다. ${ }^{2}$ 따라서 $\mathrm{HPLC}$ 방식은 $\mathrm{GC}$ 방식으로 분석이 용이 하지 않은 저분자량의 $\mathrm{CC}$ 화합물들(특히 FA 또는 $\mathrm{AA})$ 의 분석에 가장 적합한 것으로 알려져 있다. ${ }^{13}$ 또 한 HPLC를 사용할 경우, fluorescence (FL), photodiode array (PA), ultraviolet (UV) detector등 다양한 종류의 검출기를 선택적으로 사용하는 것도 가능하다. ${ }^{14,15}$ 따 라서 현재 카보닐계 화합물들에 대한 정성 및 정량분 석(기기분석법)은 주로 DNPH 카트리지에 의한 채취 그리고 HPLC에 의한 분석기법을 연계하는 방식을 중 심으로 이루어지고 있다. ${ }^{16}$

본 연구에서는 5 가지 주요 $\mathrm{CC}$ 성분들의 기체상 표준시료를 가장 기본적인 $\mathrm{CC}$ 분석기법에 해당하는 2,4-DNPH cartridge와 HPLC/UV를 연계한 분석방식 으로 조사하고자 하였다. 이를 위해, 일반적으로 쉽게
구매가 가능한 3 가지 종류의 DNPH cartridge (3 개의 제조사)를 대상으로 선정하여, 각 제품별 상대적 분석 성능을 다각도로 비교해 보고자 하였다. 이를 위하여, 악취성 CC 성분들에 대한 DNPH cartridge-HPLC/UV 방식의 회수율 및 시료 채취 단계의 편차를 파악하고 자 하였다. 참고로 이미 이러한 방식으로 FA 성분에 대한 카트리지 제품별 상대적 성능에 대한 특성을 선 행연구의 일환으로 조사한 바 있다. ${ }^{17}$ 본 연구진의 선 행연구에서는 실내공기질의 주요 연구대상 성분인 FA 를 중심으로 분석한 데 이어, 본 연구에서는 주요 지 정악취물질인 5 가지 $\mathrm{CC}$ 성분을 대상으로 연구분석을 진행하였다.

\section{2. 연구방법}

\section{1. 표준시료의 제조 및 카트리지 선정}

본 연구의 대상성분으로 선정한 5 가지 $\mathrm{CC}$ 성분들 의 gas상 표준시료를 제조하기 위하여, $10 \mathrm{ppm}$ 의 gas 상 원표준시료(primary standard (PS): Rigas, Korea)를 이용하여 작업용 표준시료(working standard: WS)를 제 조하였다. 그리고 이를 초순수 질소(Nitrogen: 이하 $\mathrm{N}_{2}$, 99.999\%)로 희석하여, 각각 $32.8-2624 \mathrm{nmol}$ 범위(AA 기준)로 총 9 가지 단계의 농도를 갖는 작업용 표준시 료를 제조하였다. 본 연구에서 선정한 5 가지 $\mathrm{CC}$ 성분 들에 대한 세부적인 정보는 Table $1 \mathrm{~A}$ 에 제시하였다.

이렇게 제조한 gas상 표준시료는 그 다음 단계에서 DNPH cartridge 방식으로 채취하고, 분석에 적용하였 다. 이 때, cartridge 제품별 성능을 비교하기 위하여, 가장 보편적으로 사용 중인 3 개 제조사의 제품 3종 ( $\mathrm{A}=$ Waters, $\mathrm{B}=$ Top trading, $\mathrm{C}=$ Supelco)을 선정하였 다. 본 연구에서 선정한 3 종의 cartridge 제품의 견본 형상은 Fig. 1에 제시하였다.

\section{2. 시료 채취 및 전처리}

비교분석을 위한 표준시료의 채취는 적산유량형 소 형펌프(SIBATA $\Sigma-300$, Japan)를 이용하여 일반적인 시 료를 공급하는 것과 유사하게 진행하였다. 이 때, 타 성분의 간섭을 최소화하기 위하여, 요오드화 칼륨 (KI)을 충진한 Sep-Pak Ozone scrubber (Waters)를 함 께 사용하였다. 시료의 채취는 $0.8 \mathrm{Lmin}^{-1}$ 의 유속으로 10 분간 총 $8 \mathrm{~L}$ 를 채취하였다. 시료를 흡수한 $\mathrm{DNPH}$ cartridge는 즉시 양쪽 끝을 밀봉시켜 주었다. 이들 시 료는 가능한 즉시 분석을 실시하거나, 냉장조건 $\left(4^{\circ} \mathrm{C}\right.$ 이하)으로 보관하였다. 
Table 1. Basic information of carbonyl compounds (CCs) and QA property (detectability)

A. A list of target compounds investigated in this study

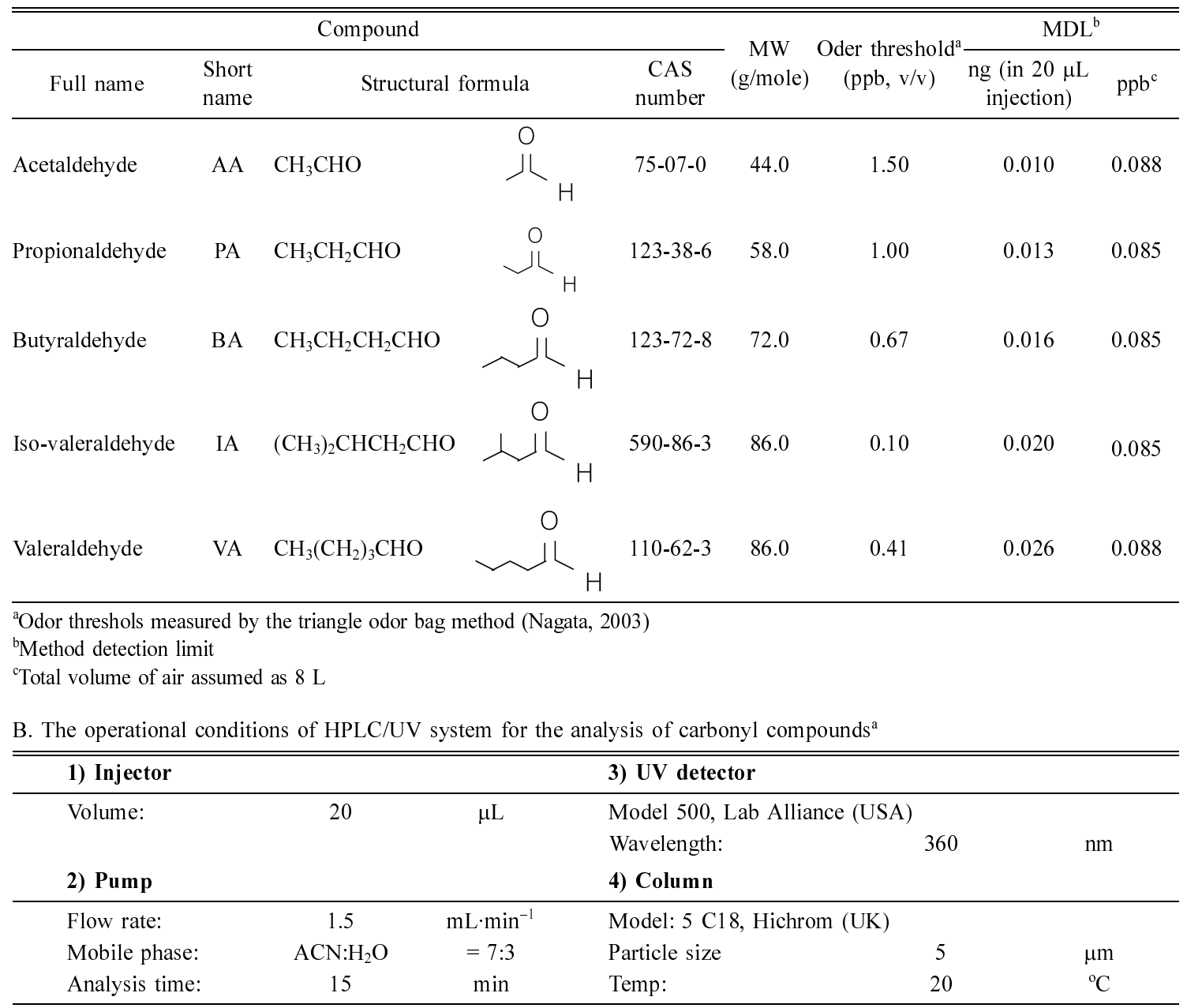

${ }^{a}$ HPLC (Series 1500, Lab Alliance, USA)

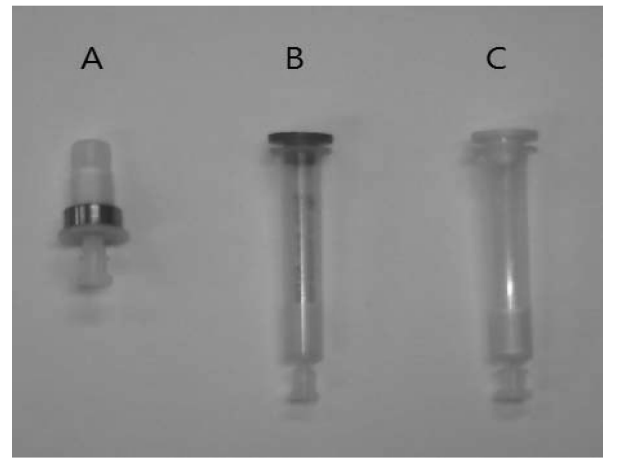

Fig. 1. Three types of cartridge products investigated in this study: (A) Waters, (B) Top trading, and (C) Supelco.
채취한 시료는 액상으로 용출하기 위하여 acetonitrile (HPLC grade, J.T. Baker) 용액 $5 \mathrm{~mL}$ 로 탈착을 유도 하였다. 용출 시에는 GHP Acrodisc $13(0.45 \mu \mathrm{m}, \mathrm{PALL})$ 을 사용하여, 타 물질의 간섭 가능성을 최소화하였다. 시료는 최초 $5 \mathrm{~mL}$ 보다 조금 부족한 양으로 용출한 후, acetonitrile을 첨가하여 정확히 $5 \mathrm{~mL}$ 로 맞추어 주 었다. 이 때, 시료의 탈착을 충분하게 유도하기 위해, 약 1 분 내외로 용출함으로써 충분한 탈착이 이루어 지도록 속도를 유지시켜 주었다.

\section{3. 분석시스템의 구성}

본 연구에서는 $\mathrm{CC}$ 성분들의 gas상 표준시료를 흡 
착한 카트리지를 액상으로 추출한 후, $\mathrm{HPLC} / \mathrm{UV}$ 시스 템으로 분석하였다. 그리고 각각의 DNPH cartridge에 대한 기본적인 분석특성을 조사하였다. 본 연구에 사 용한 HPLC/UV (Lab Alliance, Model 500)시스템은 다음과 같은 분석조건을 설정하여 분석에 활용하였다. 검출파장은 $\mathrm{DNPH}(349 \mathrm{~nm})$ 와 aldehyde 성분들의 최 대 흡광도 $(364 \mathrm{~nm})$ 를 동시에 감안하여, $360 \mathrm{~nm}$ 로 고 정하였다. HPLC용 펌프는 이중 헤드펌프(dual head pump)를 이용하여, 이동상의 압력변화에 따른 노이즈 (noise)를 최소화시켰다. DNPH 화합물의 형태로 검출 하는 비극성 $\mathrm{CC}$ 들의 효과적인 분리를 위해, 컬럼은 비극성인 HICHROM 5C18 $(25 \mathrm{~cm} \times 4.6 \mathrm{~mm}$, particle size $5 \mu \mathrm{m}$ )을 사용하였다. Acetonitrile과 water를 7:3 의 비율로 혼합한 용액을 이동상으로 사용하였다. 이 때, 시료를 안정적으로 주입하기 위하여, $20 \mu \mathrm{L}$ 루프 를 사용하여 시료를 $1.5 \mathrm{~mL} / \mathrm{min}$ 유속으로 주입하였다. 본 연구에서 운용한 기기의 자세한 설정조건은 Table $1 \mathrm{~B}$ 에 제시하였다.

Table 2. The 9-point calibration results of $\mathrm{CC}$ using 3 types of cartridge products

\begin{tabular}{|c|c|c|c|c|c|c|c|c|}
\hline \multirow{2}{*}{$\begin{array}{c}\text { DNPH } \\
\text { cartridge } \\
\text { product }\end{array}$} & \multirow{2}{*}{ Order } & \multirow{2}{*}{$\begin{array}{c}\text { Injected } \\
\text { nmol }\end{array}$} & \multirow{2}{*}{$\begin{array}{c}\text { amount } \\
\mu \mathrm{g}\end{array}$} & \multicolumn{5}{|c|}{$\overline{5} 5 \mathrm{CC}$} \\
\hline & & & & AA & PA & BA & IA & VA \\
\hline \multirow{11}{*}{ A } & 1 & 32.8 & 1.44 & 2143543 & 191594 & 181517 & 90338 & 149418 \\
\hline & 2 & 65.5 & 2.88 & 3611075 & 391644 & 423653 & 278463 & 271013 \\
\hline & 3 & 131 & 5.77 & 6858658 & 909264 & 929073 & 625781 & 725558 \\
\hline & 4 & 263 & 11.6 & 9490855 & 1573970 & 1491701 & 1413315 & 1225714 \\
\hline & 5 & 525 & 23.1 & 24437610 & 3820065 & 4065706 & 3961931 & 3427307 \\
\hline & 6 & 656 & 28.9 & 28569551 & 4413037 & 4637578 & 4699944 & 4340761 \\
\hline & 7 & 787 & 34.6 & 32821517 & 5112674 & 5376246 & 5304849 & 5138182 \\
\hline & 8 & 1312 & 57.7 & 57502503 & 9279990 & 9828213 & 10104336 & 9805540 \\
\hline & 9 & 2624 & 115 & 87520968 & 10486829 & 10241054 & 10657421 & 8905882 \\
\hline & & Calibration* & Slope value & 43504 & 34206 & 38980 & 37350 & 46223 \\
\hline & & & $\mathrm{R}^{2}$ & 0.9957 & 0.9961 & 0.9939 & 0.9890 & 0.9856 \\
\hline \multirow{11}{*}{ B } & 1 & 32.8 & 1.44 & 1546521 & 159409 & 123033 & 138400 & 133441 \\
\hline & 2 & 65.5 & 2.88 & 3504823 & 433009 & 439875 & 305341 & 309353 \\
\hline & 3 & 131 & 5.77 & 6335241 & 917230 & 910748 & 639790 & 669354 \\
\hline & 4 & 263 & 11.6 & 10654185 & 1645019 & 1644345 & 1756059 & 1493135 \\
\hline & 5 & 525 & 23.1 & 22086715 & 3283938 & 3290856 & 2950883 & 2764826 \\
\hline & 6 & 656 & 28.9 & 28097738 & 4357427 & 4507525 & 4218270 & 4146947 \\
\hline & 7 & 787 & 34.6 & 33838387 & 4848480 & 4465455 & 3304710 & 3611521 \\
\hline & 8 & 1312 & 57.7 & 52570856 & 7781188 & 7647742 & 6194790 & 6743698 \\
\hline & 9 & 2624 & 115 & 87126087 & 7110437 & 4599615 & 2756721 & 3766892 \\
\hline & & Calibration* & Slope value & 41272 & 30304 & 32100 & 25280 & 34394 \\
\hline & & & $\mathrm{R}^{2}$ & 0.9968 & 0.9958 & 0.9896 & 0.9461 & 0.9783 \\
\hline \multirow{11}{*}{$\mathrm{C}$} & 1 & 32.8 & 1.44 & 1840005 & 191441 & 194939 & 96325 & 116654 \\
\hline & 2 & 65.5 & 2.88 & 3718140 & 437258 & 466644 & 301200 & 321186 \\
\hline & 3 & 131 & 5.77 & 7534944 & 1057971 & 1144806 & 659881 & 743242 \\
\hline & 4 & 263 & 11.6 & 12757873 & 1890121 & 1992859 & 1877818 & 1688144 \\
\hline & 5 & 525 & 23.1 & 23588674 & 3274653 & 3198188 & 2873536 & 2668727 \\
\hline & 6 & 656 & 28.9 & 29605006 & 4542716 & 4670273 & 4752231 & 4506473 \\
\hline & 7 & 787 & 34.6 & 31999070 & 5009290 & 5165070 & 5179879 & 4731599 \\
\hline & 8 & 1312 & 57.7 & 47250170 & 6104637 & 6007952 & 6081288 & 5412365 \\
\hline & 9 & 2624 & 115 & 60928329 & 5929230 & 5958138 & 6712686 & 4843535 \\
\hline & & Calibration* & Slope value & 39387 & 27347 & 29685 & 27983 & 33094 \\
\hline & & & $\mathrm{R}^{2}$ & 0.9686 & 0.9138 & 0.8900 & 0.9101 & 0.8862 \\
\hline
\end{tabular}

*Calibration results drawn after excluding the max calibration point 


\section{3. 결과 및 고찰}

$\mathrm{CC}$ 성분들은 일반적으로 대기환경 중에 $\mathrm{ppb}$ 또는 그 이하의 수준으로 존재한다. 그런데 이 성분들이 대 기중에 고농도로 존재할 경우, 여러가지 환경보건학적 문제를 야기할 수도 있다. ${ }^{18}$ 따라서 악취관리의 목적 으로 환경부에서는 공업지역에 대한 이들 성분의 배 출허용기준을 $\mathrm{AA}=100, \mathrm{PA}=100, \mathrm{BA}=100, \mathrm{IA}=20$, $\mathrm{VA}=6 \mathrm{ppb}$ 로 지정하여 관리하고 있다. ${ }^{19}$ 따라서 본 연구에서는 $\mathrm{AA}$ 성분의 농도를 기준으로 비교적 낮은 농도(32.8 ppb)부터 극단적인 고농도(2624 ppb)영역까 지 DNPH cartridge 방식의 흡착범위(또는 채취 단계 의 직선성)를 최대로 확장한 조건에서 카트리지의 성 능을 비교연구하였다(Table 2).

\section{1. 정량 및 $\mathrm{QA}$}

본 연구에 사용한 분석 시스템의 특성을 평가하기 위한 가장 기본적인 수단으로 검출한계(method detection limit: $\mathrm{MDL}$ )를 평가하였다. 이는 공정시험법 에 제시한 알데하이드류의 분석방식에 따라 검출한계 에 근접한 농도수준의 시료를 제조한 후 7회 반복 측 정한 결과의 표준편차값에 3.14 를 곱하여 계산하였다 (여기서 3.14는 7 회 반복분석에 대한 $99 \%$ 신뢰수준 에서 student-t 값을 의미한다). ${ }^{20}$ 검출한계 시료의 제 조는 $15 \mu \mathrm{g} / \mathrm{mL}$ 농도수준의 액상표준시료(aldehyde/ keton-DNPH mix, supelco, USA)를 사용하였다. 실험
결과 분석 시스템의 $\mathrm{MDL}$ 은 성분별로 $0.01 \sim 0.03 \mathrm{ng}$ 수준으로 나타났다. 이를 편의상 일반적인 시료 채취 량(Gas volume)에 해당하는 $8 \mathrm{~L}$ 수준으로 가정하면 모두 $0.9 \mathrm{ppb}$ 의 농도대에 해당한다(Table 1A).

3 종의 cartridge 제품에 대한 상대적 성능을 비교하 기 위해, 우선적으로 재현성을 평가해 보았다. 이를 위해, 동일 농도의 표준시료를 각각 채취 후 용출하는 방식으로 생성한 액상 시료를 3 회 반복 분석하는 방 식으로 상대 표준오차(relative standard error: RSE= (SE/mean) $\times 100, \%)$ 를 산출하였다(여기에서 $\mathrm{SE}=3$ 회 반복 분석한 측정치의 표준오차: Mean = 반복분석 측 정치의 평균). 그리고 이를 3 가지 제품에 대하여 각 각 성분별로 RSE를 정리하여 제시하였다(Table 3). 그 결과, 대부분의 성분들에 대한 재현성은 3 종의 cartridge 모두 $5 \%$ 이내로 좋은 결과를 보였다. 그러나 $\mathrm{A}$ 제품의 경우 $\mathrm{IA}=6.64, \mathrm{VA}=5.00 \%$ 로 다소 불안정한 모습을 보였다. $\mathrm{B}, \mathrm{C}$ 제품은 5 가지 성분 모두 $\mathrm{RSE}$ 값이 $5 \%$ 이하로 나타났다. 특히, B 제품의 경우 5 가지 성분에 서 모두 최소 $0.14 \%$ 부터 최대 $1.75 \%$ 까지 가장 안정 적인 RSE값을 보였다.

\section{2. $\mathrm{DNPH}$ cartridge별 blank 평가}

$\mathrm{DNPH}$-cartridge 방식으로 시료를 채취할 경우, 채취 대상인 $\mathrm{CC}$ 성분들이 이미 제품공정상 일정 수준 오 염에 노출되는 경우가 대부분이다. 이러한 부분을 고 려하지 않고 분석을 진행할 경우, 저농도 시료들은

Table 3. Comparison of reproducibility (relative standard error (RSE)) of 5 carbonyl compounds for 3 of cartridge types

\begin{tabular}{clrrr}
\hline \hline $\begin{array}{c}\text { Carbonyl } \\
\text { compounds }\end{array}$ & Sample ID & \multicolumn{1}{c}{ A } & \multicolumn{1}{c}{ B } & C \\
& Manufacturer & Waters & Top trading & Supelco \\
\hline \multirow{3}{*}{ AA } & Mean & 22518559 & 21599903 & 19623336 \\
& SD & 190907 & 51997 & 278158 \\
& RSE (\%) & 0.49 & 0.14 & 0.82 \\
\cline { 2 - 5 } PA & Mean & 3233017 & 2846270.667 & 2301154 \\
& SD & 119916 & 16275 & 71404 \\
& RSE (\%) & 2.14 & 0.33 & 1.79 \\
\cline { 2 - 5 } BA & Mean & 3168367 & 1981230 & 2176122 \\
& SD & 195690 & 18111 & 101658 \\
& RSE (\%) & 3.57 & 0.53 & 2.70 \\
\cline { 2 - 5 } IA & Mean & 3071540 & 602092 & 101360 \\
& SD & 353210 & 18248 & 2.82 \\
& RSE (\%) & 6.64 & 1.75 & 1719386 \\
& Mean & 2644954 & 1101390 & 142143 \\
VA & SD & 228836 & 21393 & 4.77 \\
& RSE (\%) & 5.00 & 1.12 & \\
\hline
\end{tabular}


Table 4. Comparison of blank run test results for 3 of cartridge types

A. Blank concentration $(n=4)^{a}$

\begin{tabular}{cccc}
\hline \hline Sample ID & Compounds & AA & PA \\
\hline A & $\mathrm{ppb}^{\mathrm{b}}$ & 23.7 & 0.55 \\
(Waters) & $\mathrm{SD}$ & 2.83 & 1.10 \\
\hline $\mathrm{B}$ & $\mathrm{ppb}^{\mathrm{b}}$ & 0 & 0 \\
(Top trading) & $\mathrm{SD}$ & 0 & 0 \\
\hline $\mathrm{C}$ & $\mathrm{ppb}^{\mathrm{b}}$ & 11.8 & 0 \\
(Supelco) & $\mathrm{SD}$ & 11.6 & 0 \\
\hline
\end{tabular}

${ }^{\mathrm{a}} \mathrm{BA}, \mathrm{IA}$ and VA compounds were not detected

${ }^{\mathrm{b}}$ Assuming the sample volume as $8 \mathrm{~L}$

B. Percent error values

\begin{tabular}{cccccccc}
\hline \hline \multirow{2}{*}{$\begin{array}{c}\text { Carbonyl } \\
\text { compounds }\end{array}$} & \multicolumn{3}{c}{ Mean (\%) } & & \multicolumn{3}{c}{ Standard deviation (\%) } \\
\cline { 2 - 3 } \cline { 7 - 8 } & A & B & C & & A & B & C \\
\hline AA & 6.72 & 5.18 & 15.3 & & 22.7 & 13.9 & 28.4 \\
PA & -8.60 & -3.81 & 10.2 & & 14.3 & 22.3 & 31.4 \\
BA & -12.3 & -7.86 & 11.5 & & 16.6 & 28.4 & 33.6 \\
IV & -23.9 & -5.17 & -6.78 & & 24.0 & 33.1 & 30.6 \\
VA & -21.6 & -9.82 & -1.49 & & 19.6 & 26.6 & 31.4 \\
\hline Mean & -11.9 & -4.3 & 5.8 & & 19.5 & 24.8 & 31.1 \\
\hline
\end{tabular}

blank값으로 인해 상대적으로 매우 큰 오차가 발생할 수 있다. ${ }^{17}$ 따라서 정량분석 전 단계에 cartridge 내부 의 자체적인 blank 수준을 확인하고, 이를 보정에 활 용하는 것이 상당히 중요하다. 본 연구에서는 이러한 점을 감안하여, 3 가지의 cartridge 제품들에 대한 blank 농도의 수준을 5 가지 $\mathrm{CC}$ 성분들 각각에 대하여 조사 하였다. 아무런 시료도 채취하지 않은 상태의 사용 전 cartridge를 acetonitrile용액으로 용출하여 HPLC/UV 시스템으로 분석하였다. 이러한 방법으로 3 종 카트리 지를 대표할 수 있게, 각 제조사별로 4 개씩의 cartridge 를 선정하여 분석을 실시하였다. 그리고 이러한 replicate 시료의 분석결과로부터 각 제조사별 cartridge 제품의 blank 평균값을 산출하였다(Table 4A). 그 결 과, $\mathrm{A}$ 제품의 경우 $\mathrm{AA}=23.7( \pm 2.83) \mathrm{ppb}, \mathrm{PA}=0.55$ $( \pm 1.1) \mathrm{ppb}$ 수준의 cartridge blank가 나타났다. C 제품 의 경우 $\mathrm{AA}$ 성분만 $11.8( \pm 11.6) \mathrm{ppb}$ 수준으로 blank 값이 나타났다. $\mathrm{B}$ 제품의 경우 $\mathrm{AA}, \mathrm{PA}$ 성분의 cartridge blank가 모두 나타나지 않았다. BA, IA, VA성분의 경 우, 3 종의 cartridge에서 모두 검출되지 않았다. 따라 서 cartridge blank 값의 크기를 감안할 경우, 제품 $\mathrm{A}$ 는 $\mathrm{AA}$ 와 $\mathrm{PA}$ 성분을 정 량분석하는데 비교적 큰 오차를 발생시킬 소지가 있다. 제품 $\mathrm{C}$ 에서도 마찬가지로 $\mathrm{AA}$ 성분에 대한 blank 값이 다소 높은 수준으로 존재하였 다. 전반적으로 blank 값의 안정도는 $\mathrm{B}, \mathrm{A}, \mathrm{C}$ 제품 순 으로 파악되었다. 또한 제품 $\mathrm{B}$ 의 경우, 5 가지 $\mathrm{CC}$ 성 분들에 대한 blank가 나타나지 않기 때문에, 정량분석 에 blank의 영향이 가장 미미할 것으로 판단된다. 이 러한 점을 종합적으로 감안하면, $\mathrm{AA}, \mathrm{PA}$ 성분들을 포 함한 CC 성분들을 DNPH-cartridge 방식으로 분석할 경우, 매 실험시 blank를 반드시 확인해야 할 필요가 있다.

\subsection{DNPH cartridge별 Carbonyl 성분들에 대한 상대감도의 비교 평가}

$\mathrm{CC}$ 성분들에 대한 DNPH cartridge의 회수율을 평 가하기 위하여, 본 실험은 총 9 단계의 농도를 대표하

Table 5. Comparison of calibrated linearity in relation to the maximum number of calibration points

\begin{tabular}{|c|c|c|c|c|c|c|c|c|c|c|}
\hline \multirow{2}{*}{$\begin{array}{l}\text { Carbonyl } \\
\text { compounds }\end{array}$} & \multirow{2}{*}{$\begin{array}{c}\text { Calibration } \\
\text { values }\end{array}$} & \multicolumn{3}{|c|}{9 points } & \multicolumn{3}{|c|}{8 point } & \multicolumn{3}{|c|}{7 points } \\
\hline & & $\mathrm{A}$ & $\mathrm{B}$ & $\mathrm{C}$ & $\mathrm{A}$ & B & $\mathrm{C}$ & $\mathrm{A}$ & $\mathrm{B}$ & $\mathrm{C}$ \\
\hline \multirow{2}{*}{ AA } & Slope value & 36258 & 35726 & 28279 & 43504 & 41272 & 39387 & 43118 & 42742 & 43492 \\
\hline & $\mathrm{R}^{2}$ & 0.941 & 0.9736 & 0.812 & $0.9957^{\mathrm{a}}$ & 0.9968 & 0.9686 & 0.9893 & 0.9984 & 0.9863 \\
\hline \multirow{2}{*}{ PA } & Slope value & 24310 & 18709 & 16251 & 34206 & 30304 & 27347 & 33187 & 31422 & 32567 \\
\hline & $\mathrm{R}^{2}$ & 0.8384 & 0.6092 & 0.4094 & 0.9961 & 0.9958 & 0.9138 & 0.9939 & 0.9967 & 0.9922 \\
\hline \multirow{2}{*}{ BA } & Slope value & 26558 & 16498 & 17645 & 38980 & 32100 & 29685 & 37611 & 33183 & 35961 \\
\hline & $\mathrm{R}^{2}$ & 0.7879 & 0.2086 & 0.328 & 0.9939 & 0.9896 & 0.89 & 0.9895 & 0.9817 & 0.9868 \\
\hline \multirow{2}{*}{ IA } & Slope value & 25869 & 11581 & 17689 & 37350 & 25280 & 27983 & 35187 & 26846 & 33368 \\
\hline & $\mathrm{R}^{2}$ & 0.8147 & -0.094 & 0.5821 & 0.989 & 0.9461 & 0.9101 & 0.9852 & 0.9064 & 0.9764 \\
\hline \multirow{2}{*}{ VA } & Slope value & 29847 & 17272 & 18723 & 46223 & 34394 & 33094 & 42499 & 34996 & 40248 \\
\hline & $\mathrm{R}^{2}$ & 0.7244 & 0.174 & 0.306 & 0.9856 & 0.9783 & 0.8862 & 0.9893 & 0.9515 & 0.9744 \\
\hline
\end{tabular}

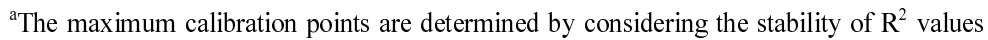




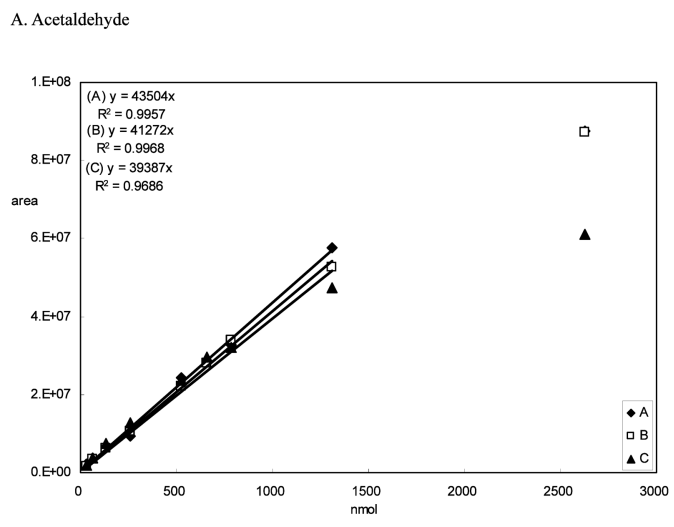

B. Propionaldehyde

C. Butylaldehyde
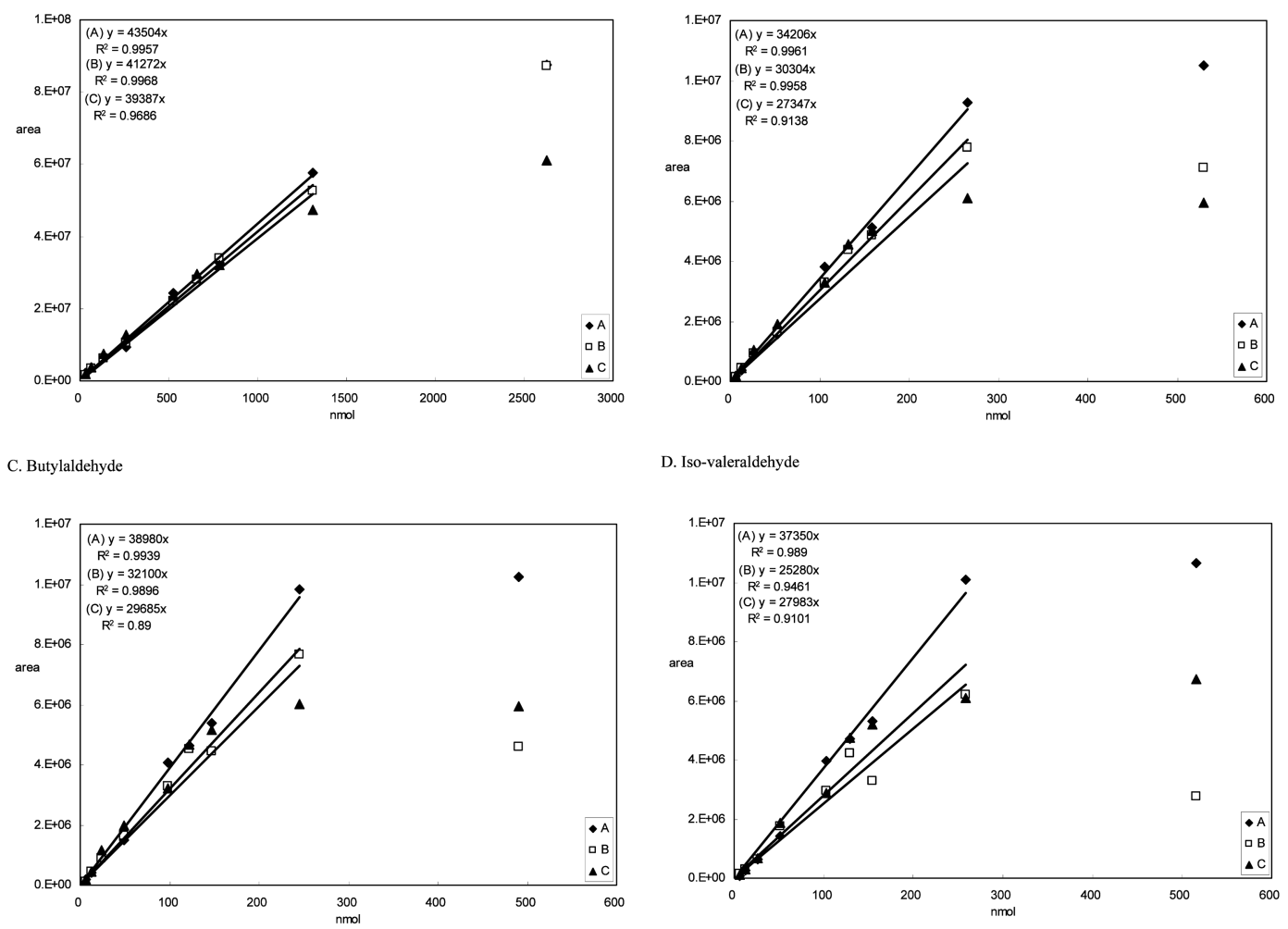

D. Iso-valeraldehyde

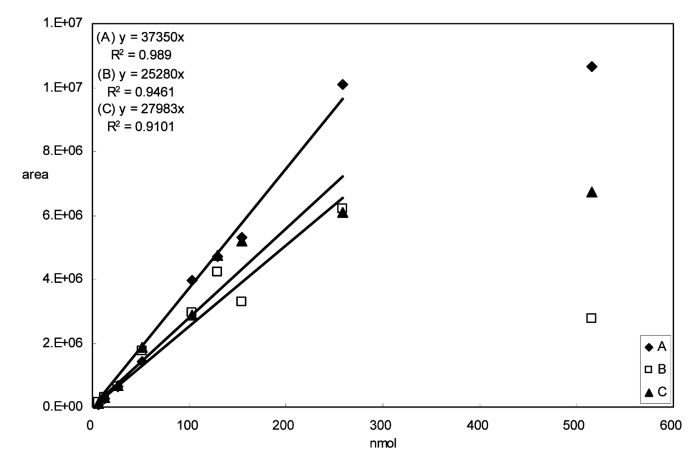

E. Valeraldehyde

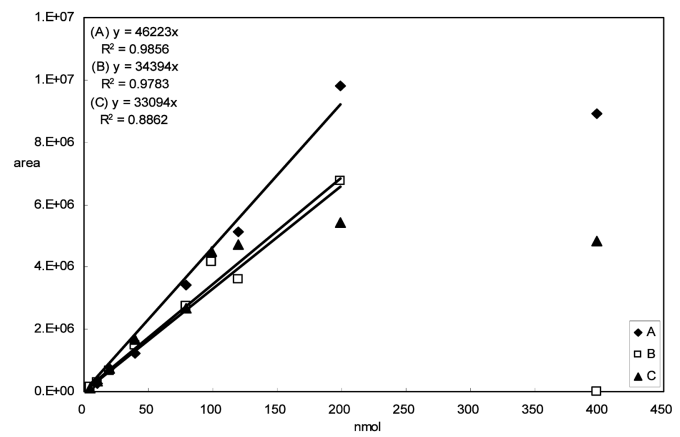

Fig. 2. Comparison of dynamic linearity ranges of each $\mathrm{CC}$ between three types of cartridge products.

는 작업용 표준시료를 준비하여, 다음과 같이 비교분 석을 시도하였다(Table 2). 9 점 검량 자료를 이용한 각 cartridge별 검 량선으로부터 5 가지 $\mathrm{CC}$ 성분들에 대한 상대적 감도의 차를 파악하였다. 이들 분석결과 는 Table 5에 제시한 바와 같이, 최대 검량점까지 확 보한 자료에서 $\mathrm{R}^{2}$ 값의 변동성을 감안하여, 직선성이 제한을 받지 않는 최대 검량 영역을 확인해 보았다.
우선 $\mathrm{AA}$ 성분의 경우, 8 번째 검량점까지 포함하였 을 때, 3 개사의 제품별 기울기는 각각 $\mathrm{A}=43504, \mathrm{~B}=$ $41272, \mathrm{C}=39387$ 로 가장 양호한 감도를 보였다. 그러 나 다른 4 가지 성분들을 살펴 본 결과, 제품별 직선 성의 영역에 다시 구분이 이루어지는 모습을 관찰할 수 있었다. Table 5의 결과를 보면, A와 B사의 제품은 5 가지 $\mathrm{CC}$ 모두 최대 8 점 검량단계에서 최적의 직선 
성을 확보할 수 있다. 반면 $\mathrm{C}$ 사의 제품은 $\mathrm{AA}$ 를 제외 할 경우, 모두 8 점 검량의 결과에서 직선성이 감소하 는 것을 볼 수 있다. 반면 이들의 검량결과를 7점 선 에 맞추어 주면, 다시 양호한 상태를 회복한다. 결과 적으로 $\mathrm{A}, \mathrm{B}$ 사의 제품에 비해 $\mathrm{C}$ 사 제품의 경우, 현저 하게 직선성 영역의 제한이 따른다는 것을 볼 수 있 다. 이는 제품별로 직선성의 제한, 즉 cartridge에서 흡 수능의 한계(즉, 파과현상) 또는 이들 제품과 경합한 상태의 HPLC 기기 자체에서 직선성의 차별화가 현저 한 것으로 볼 수 있다. 그리고 이러한 분석 결과는 제 품별로 상대 감도의 차이가 뚜렷하게 나타난다는 것 을 시사한다. 7 또는 8 점 검량의 결과를 이용하여 산 출한 기울기값을 비교하면, 전반적으로 $\mathrm{A}>\mathrm{C}>\mathrm{B}$ 또 는 $\mathrm{A}>\mathrm{B}>\mathrm{C}$ 의 순으로 기울기 값이 감소하는 경향이 모든 성분들에서 나타난다.

이러한 점들을 종합적으로 감안하면, DNPH cartridge 방식을 적용하여 악취성 $\mathrm{CC}$ 성분들을 포함한 시료를 채취분석할 때 성분별 직선성 영역의 차이를 확인할 필요가 있다. 보다 구체적으로 $\mathrm{AA}$ 와 같은 저분자 성 분들은 $50 \mu \mathrm{g}$ 수준까지는 직선성을 유지하는 영역에 서 정량분석이 가능하다. 그리고 각 제품들간에 상대 적 감도의 차이도 현저하게 나타난다. 이러한 제품별 특성도 화합물의 종류에 따라 다시 민감하게 구분이 이 루어지는 경향을 알 수 있다. 특히 대상시료의 농도 또 는 분자량이 증가할 경우, $\mathrm{CC}$ 의 상대감도는 $\mathrm{B}$ 와 $\mathrm{C}$ 제 품에 비해 $\mathrm{A}$ 제품이 상대적으로 좋은 결과를 보였다.

\subsection{DNPH cartridge별 Carbonyl 성분들에 대한 회수율 평가}

앞 절의 실험결과에서 carbonyl성분들에 대한 $\mathrm{DNPH}$ cartridge의 성능을 직선성 또는 상대감도의 변화에 대 한 관계로 비교평가해 보았다. 이를 통해, 간접적으로

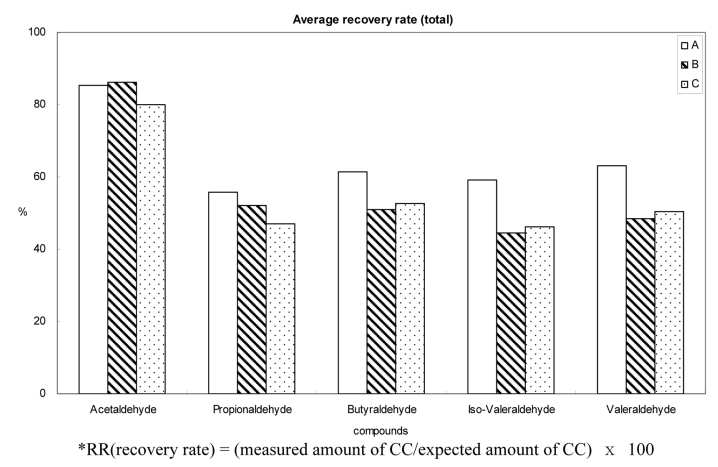

Fig. 3. Comparison of recovery rate for 5 carbonyl compounds.
$\mathrm{CC}$ 들에 대한 각 제품의 특성을 어느 정도 파악할 수 있었다. 이들 제품의 성능을 평가하기 위한 또 한가지 방법으로 액상 표준시료의 검량 기울기 값을 이용하 여 매 분석 시 카트리지로 흡수한 기체상 표준시료의 농도 값을 산출하였다. 그리고 이를 시료 준비 단계에 설정한 표준시료의 주입농도와 대비함으로써, 시료의 회수율을 평가해보고자 하였다. 이를 위하여, 각 농도 대에서 각 성분에 대한 제품별 회수율(recovery rate= (measured amount of CC/expected amount of CC) $\times 100$, $\%$ )을 계산하였다. 그리고 이들 농도대별 자료의 평균 치를 산출하여 Fig. 3에 제시하였다.

우선 $\mathrm{AA}$ 성분에 대한 3 가지 제품의 회수율은 각각 $\mathrm{A}=85.5, \mathrm{~B}=86.2, \mathrm{C}=80.0 \%$ 로 양호하게 나타났다. 이 경우, $\mathrm{B}$ 제품이 다른 2 가지 제품에 비해 다소 높 은 회수율을 보였으나, 통계적 유의성은 없는 것으로 사료된다. 그러나 다른 4 가지 $\mathrm{CC}$ 성분들에 대한 회수 율은 3 가지 제품 모두 $40-60 \%$ 수준으로 낮은 회수율 을 보였다. 대표적으로 $\mathrm{VA}$ 성분의 경우, $\mathrm{A}=63.0$, $\mathrm{B}=48.3, \mathrm{C}=50.3 \%$ 로 나타났다. 이러한 현상을 감안할 경우, 현재 보급중인 $\mathrm{DNPH}$ 카트리지 제품들이 실내 공기질의 대표적인 주요성분인 $\mathrm{FA}$ 나 대기 악취물질의 주요성분인 $\mathrm{AA}$ 와 같이 저분자 $\mathrm{CC}$ 의 채취에 가장 높 은 회수율을 보인다는 것을 알 수 있다. 반면, 상대적 으로 분자량이 큰 $\mathrm{CC}$ 의 채취능력이 상당히 떨어지는 것을 알 수 있다. 또한 이들 4가지 성분들의 경우, 공 통적으로 $\mathrm{A}$ 제품이 다른 2 가지 제품에 비해 약 $10 \%$ 정도의 차이로 보다 양호한 회수율을 보였다. 반면, 다른 2 가지 제품은 회수율의 차이가 약 $1 \sim 2 \%$ 범위 로 근소하게 나타났다. 참고로 본 연구와 유사한 조건 으로 formaldehyde (FA) 성분에 대한 회수율을 위의 방식으로 산출한 경우, 3 가지 제품 모두 넓은 범위의 농도(44 3403 ppb)에서 모두 90\% 이상의 회수율을 꾸준히 유지하는 것으로 나타났다.

\subsection{Carbonyl compounds 농도와 DNPH cartridge의 회수율}

앞절의 실험결과에서 $\mathrm{CC}$ 성분의 농도별, 제품별 DNPH cartridge의 회수율을 파악해 보았다. 이러한 결 과를 바탕으로, $\mathrm{CC}$ 성분들의 분석오차의 발생 특성을 보다 구체적으로 파악하기 위하여, 다음과 같이 추가 적인 분석을 시도하였다. 이를 위해 기체상 표준시료 를 cartridge로 흡수한 후 HPLC로 실제 액상표준시료 를 검량하여 분석결과와 비교하면, 전반적으로 표준시 료를 제조할 때 예상한 농도보다 낮게 나타났다. 결과

Vol. 23, No. 5, 2010 

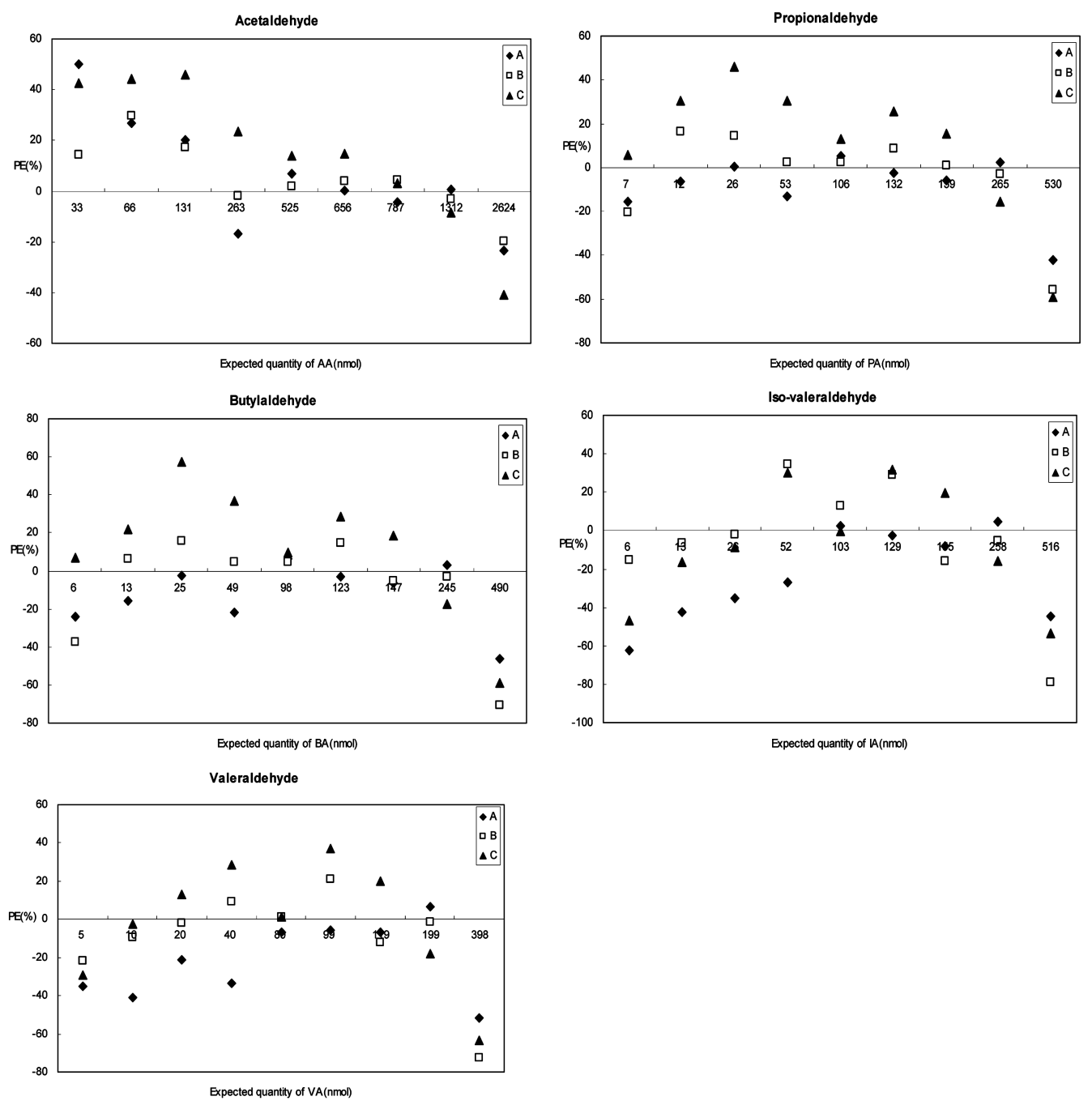

*Percent Error $(\mathrm{PE})=$ (measured amount of CC - expected amount of CC) / expected amount of CC x 100

Fig. 4. Comparison of 5 carbonyl compounds percent errors as a function of standard concentration.

적으로 카트리지에 흡수를 유도한 기체상 표준시료는 일부 또는 상당부분 회수가 이루어지지 않는다고 볼 수 있다. 따라서 예상치와 실제치의 차이를 percent error (PE in \%=[(expected amount of CC-measured amount of $\mathrm{CC}) /($ expected amount of $\mathrm{CC})] \times 100$ 로 표 현하였다(Fig. 4).

$\mathrm{AA}$ 성분의 경우 각 제품별로 어느 정도 $\mathrm{PE}$ 값의 차 이가 존재하였으나, 농도의 증가에 따른 $\mathrm{PE}$ 의 변화추 이는 유사하게 나타났다. 즉, 본 연구에서 설정한 총 9 단계의 농도 중 저농도에 해당하는 $33 \sim 131 \mathrm{nmol}$ 구간에서는 3 가지 제품에서 모두 일관적으로 25 $\sim 50 \%$ 수준의 오차를 나타냈다. 그리고 중간농도부터 고농도대인 263 1312 nmol 구간에서는 PE값이 0에 가까운 음의 영역부터 양의 영역사이, 즉 $-8 \sim 10 \%$ 이 내로 가장 안정적인 경향을 나타났다. 이러한 안정적 인 경향은 최대농도로 설정한 $2624 \mathrm{nmol}$ 에서 3 가지 제품 모두 $-20 \sim-40 \%$ 대로 급격하게 하락하면서 큰 폭 으로 음의 오차를 나타냈다. 이는 고농도에서 직선성 이 제한받는 분석 특성을 반영한데 따른 결과로 볼 수 있다.

$\mathrm{AA}$ 성분을 제외한 다른 4 가지 $\mathrm{CC}$ 성분들( $\mathrm{PA}, \mathrm{BA}$, $\mathrm{IA}, \mathrm{VA})$ 의 경우, $\mathrm{AA}$ 와는 또 다른 양상을 취하며 거의 
유사하게 나타났다. 즉, 저농도대에 해당하는 3번째 농 도대까지는 음의 영역부터 양의 영역까지 큰 폭(30 $\sim 40 \%$ )으로 변화하며 PE 값이 증가하는 경향을 보였다, 그리고 중간농도부터 8 번째 농도인 고농도대까지 완만 한 폭(약 $15 \%$ 내외)으로 감소하며 가장 안정적인 경향 을 나타냈다. 그리고 AA 성분과 마찬가지로 나머지 성 분들은 최대농도에서는 3 가지 제품 모두 $-40 \sim-70 \%$ 까 지 급격하게 음의 오차가 증가하는 경향을 보였다.

5 가지 CC성분의 검량결과들이 모두 시료의 농도 변화에 따라 영향을 받는다는 점을 감안하여, 3 가지 제품의 각 성분별 $\mathrm{PE}$ 의 평균과 $\mathrm{SD}$ 값을 이용하여 전 체적인 안정도를 비교해 보았다. 그 결과, $\mathrm{A}=-11.9$ $( \pm 19.5), \mathrm{B}=-4.3( \pm 24.8), \mathrm{C}=5.8( \pm 31.1) \%$ 로 나타났다 (Table 4B). 이는 A 제품이 농도변화에 가장 영향을 작게 받으며, 안정적인 회수율을 보였다고 판단할 수 있다. 그리고 $\mathrm{C}$ 제품이 $\mathrm{PE}$ 값이 농도변화에 따라 가장 큰 편차를 보이며 불안정하다고 볼 수 있다.

\section{4. 요약 및 결론}

본 연구에서는 2,4-DNPH cartridge와 HPLC/UV 시 스템을 연계한 분석방식을 이용하여, DNPH cartridge 제품들의 상대적 성능을 5 가지 $\mathrm{CC}$ 성분들의 분석에 직접 적용하는 방식으로) 평가하였다. 이러한 연구에 서 각기 다른 3 종의 DNPH cartridge를 사용하여, 제 조사별 제품의 상대적인 성능도 동시에 평가하였다. 이를 위해, 총 9 단계의 농도로 준비한 $\mathrm{CC}$ 의 기체상 표준시료를 이용하여 검량결과를 확보하였다.

3 종의 cartridge제품에 대한 상대적 성능을 비교하기 위해, 우선적으로 재현성을 RSE값으로 평가해 보았다. 그 결과, $\mathrm{B}$ 제품이 5 가지 $\mathrm{CC}$ 성분에 대하여 가장 작은 $\mathrm{RSE}$ 값으로 안정적인 경향을 보였다. Cartridge별 blank 측정에서는 $\mathrm{BA}, \mathrm{IA}, \mathrm{VA}$ 성분의 경우 3 종의 cartridge에 서 모두 검출되지 않았다. 반면, $\mathrm{AA}$ 와 $\mathrm{PA}$ 성분은 제조 사별로 다른 blank의 양상을 보였다. 제품별 $\mathrm{CC}$ 성분 의 직선성을 알아보기 위해, 검량 기울기값을 이용한 상대적인 비교를 진행하였다. 그 결과 $\mathrm{A}, \mathrm{B}$ 제품에 비 해 $\mathrm{C}$ 제품의 직선성이 상대적으로 민감하게 제한받는 것을 확인할 수 있었다. 그리고 검량 기울기의 절대값 크기에 대한 비교를 통해, 대상 제품별 상대적 감도의 차이를 구분하였다. 그 결과 5 가지 $\mathrm{CC}$ 성분들에 대한 제품별 회수능은 $\mathrm{A}, \mathrm{B}, \mathrm{C}$ 제품순으로 나타났다. 마지막 으로 회수능의 변화추이를 액상시료에 대비하여 기체 상 표준시료를 cartridge 방식으로 분석할 때의 회수율
을 감안하여 퍼센트 오차값(PE, \%)으로 평가하였다. 그 결과, 제품별 안정도는 $\mathrm{A}, \mathrm{B}, \mathrm{C}$ 순으로 나타났다.

본 연구의 결과 2,4-DNPH cartridge와 $\mathrm{HPLC} / \mathrm{UV}$ 시스템을 연계한 방식으로 $\mathrm{CC}$ 분석을 할 때, cartridge blank 측정의 중요성을 확인할 수 있다. 또한 $\mathrm{AA}$ 를 제외한 상대적인 고분자 $\mathrm{CC}$ 들의 $\mathrm{DNPH}$ cartridge에 대한 회수능은 감소하는 것으로 나타났다. 그리고 이 러한 관점에서, 전체적으로 $\mathrm{A}$ 제품이 가장 양호한 회 수율을 보이는 것으로 나타났다. 본 연구에서 설정한 9 단계 농도대 중 7,8 단계에서는 cartridge 제품의 종류에 따라 성분별 직선성의 제한영역에 차이가 나 타나는 것을 확인하였다. 이러한 점을 감안하면, 분석 대상 $\mathrm{CC}$ 성분에 대한 이상적인 농도범위와 cartridge 의 특성을 파악하는 것이 $\mathrm{CC}$ 성분의 정확한 분석에 중요한 요인으로 작용한다는 것을 알 수 있다. 또한 차후 2,4-DNPH cartridge 방식에 대한 적용범위(성분 의 다양화, 농도영역별 감도나 직선성 특징)를 보다 넓게 잡고 여러가지 객관적인 분석기준을 정립하고 제시하기 위한 후속연구가 필요하다.

\section{참고문헌}

1. "개정악취방지법" Korean Ministry of Environment (2008).

2. S. Uchiyama, Y. Inaba and N. Kunugita, J. Chromatogr. A, 6, 1-6(2010).

3. M. J. Fedoruk and B. D. Kerger, J. Expo. Anal. Environ Epidemiol., 13, 31-41(2003).

4. M. Onishi, Y. Sekine, K. Sugihara, K. Kitasaka and H. Shimajiri, J. Health Sci., 53(4), 413-422(2007).

5. J. O. Levin, R. Lindahi and K. Andersson, J. Air Pollut. Control Assoc., 39, 44-47(1989).

6. S. Uchiyama, E. Matsushima, H. Tokunaga, Y. Otsubo, M. Ando, J. Chromatogr. A, 1116, 165-171(2006)

7. D. Grosjean, Environ. Sci. Technol., 116, 254-262(1982).

8. K. Kuwata, M. Uebori, H. Yamasaki, Y. Kuge and Y. Kiso, Anal. Chem., 55, 2013-2016(1985).

9. T. Schmitz, D. Hassel and F. J. Weber, Atm. Environ., 34, 4639-4647(2000).

10. 조덕희, 송일석, 김인구, 김웅수, 김종보, 김태현, 황 선민, 남우경, 대한위생학회지, 21(1), 35-43(2006).

11. R. Pal and K. H. Kim, Anal. Chim. Acta, 610, 289296(2008).

12. 정지연, 박승현, 이광용, 오세민, 한국산업위생학회지, 
10(1), 126-147(2000).

13. M. Possanzini and V. D. Palo, Chromatogrphia, 46(5/6), 235-240(1997).

14. M. Possanzini, V. D. Palo and A. Cecinato, Atm. Environ., 37, 1309-1316(2003).

15. K. H. Kim, Y. J. Hong, R. Pal, E. C. Jeon, Y. S. Koo and S. W. Young, Chem., 70, 807-820(2008).

16. B. P. Andreini, R. Baroni, E. Galimberti and G. Sesana,
Microchem. J., 67, 11-19(2000)

17. 홍원필, 임승민, 김기현, 이은희, 김윤신, 한국실내환 경학회지, 7(3), 135-146(2010).

18. D. Sin and V. Jack, Respir. Crit. Care Med., 164(4), 580-584(2001).

19. “배출허용기준”, 환경부, 2007.

20. “악취공정시험방법”, 환경부, 2008. 